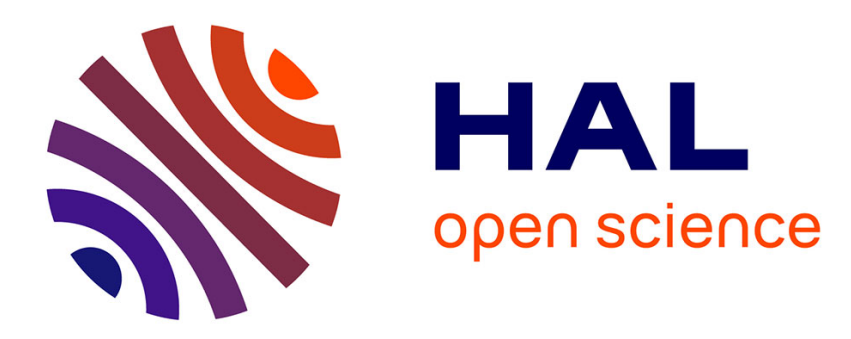

\title{
Ultrasonic Study of YBa2Cu3O7-x Superconductors
}

T. Takanohashi

\section{To cite this version:}

T. Takanohashi. Ultrasonic Study of YBa2Cu3O7-x Superconductors. Journal de Physique IV Proceedings, 1996, 06 (C8), pp.C8-473-C8-476. 10.1051/jp4:19968102 . jpa-00254530

\section{HAL Id: jpa-00254530 https://hal.science/jpa-00254530}

Submitted on 1 Jan 1996

HAL is a multi-disciplinary open access archive for the deposit and dissemination of scientific research documents, whether they are published or not. The documents may come from teaching and research institutions in France or abroad, or from public or private research centers.
L'archive ouverte pluridisciplinaire HAL, est destinée au dépôt et à la diffusion de documents scientifiques de niveau recherche, publiés ou non, émanant des établissements d'enseignement et de recherche français ou étrangers, des laboratoires publics ou privés. 
JOURNAL DE PHYSIQUE IV

Colloque C8, supplément au Journal de Physique III, Volume 6, décembre 1996

\title{
Ultrasonic Study of $\mathrm{YBa}_{2} \mathrm{Cu}_{3} \mathrm{O}_{7-x}$ Superconductors
}

\author{
T. Takanohashi
}

Fujitsu Laboratories Ltd., 10-1 Morinosato-Wakamiya, Atsugi 243-01, Japan

\begin{abstract}
We investigated the mechanical properties of the sintered $\mathrm{YBa}_{2} \mathrm{Cu}_{3} \mathrm{O}_{7-\mathrm{x}}$ superconductors from the view point of the porosity and elastic anomalies. In the highly textured sample $\left(5.93 \mathrm{~g} / \mathrm{cm}^{3}\right.$, porosity of $7 \%$ ), the Debye temperature was $440 \mathrm{~K}$ determined from the longitudinal and transverse velocities $\left(\mathrm{V}_{1}=4.9 \mathrm{~km} / \mathrm{s}\right.$, and $\mathrm{V}_{\mathrm{t}}=3.2$ $\mathrm{km} / \mathrm{s}$ ), which agreed very well with those measured by the specific heat and Mossbauer experiments ever reported. The background attenuation due to the grain-boundary scattering was $7 \mathrm{~dB} / \mathrm{cm}$ at $9.7 \mathrm{MHz}$ - longitudinal ultrasonic mode. On the other hand, in the porous sample $\left(4.7 \mathrm{~g} / \mathrm{cm}^{3}\right.$, porosity of $25 \%$ ), the Debye temperature was $320 \mathrm{~K}$ determined from the velocities of $V_{l}=3.5 \mathrm{~km} / \mathrm{s}$ and $V_{t}=2.3 \mathrm{~km} / \mathrm{s}$, and the background attenuation was $10 \mathrm{~dB} / \mathrm{cm}$ at 9.7 MHz - longitudinal mode. Some kinds of elastic anomalies were observed. In the sample $\left(x=0.53\right.$, $T_{\mathfrak{c}}$ the steplike attenuation was detected just above $T_{c}(2 \mathrm{~dB} / \mathrm{cm})$, which was the ultrasonic absorption due to the lattice instability, and essentially related to the superconducting transition. The relaxation-type sharp peak was observed $(9$ $\mathrm{dB} / \mathrm{cm}$ at $62 \mathrm{~K})$ in the sample of $\mathrm{YBa}_{2} \mathrm{Cu}_{3} \mathrm{O}_{7-\mathrm{x}}\left(\mathrm{x} \approx 0, \mathrm{~T}_{\mathrm{c}} \approx 90 \mathrm{~K}\right)$, with a narrow temperature width of $15 \mathrm{~K}$. It was due to the ultrasonic absorption by jump motion of oxygen atoms between two stable sites.
\end{abstract}

\section{INTRODUCTION}

Ultrasonic method, a powerfull tool for studies of the metal superconductors, has been also applied to the the high- $\mathrm{T}_{\mathrm{c}}$ cuprate superconductors in order to clarify the superconductivity mechanism through the elastic properties. Levy reviewed the many studies of ultrasonic measurements of the cuprate superconductors [1]. Wu-Ting and Fossheim surveid on the elastic anomalies - lattice instabilities, and discussed their mechanisms [2]. Dominec et al. summarized the elastic constants of $\mathrm{Bi}-\mathrm{Sr}-\mathrm{Ca}-\mathrm{Cu}-\mathrm{O}$ (BSCCO), $\mathrm{La}-\mathrm{Sr}-\mathrm{Cu}-$ $\mathrm{O}$ (LSCO), and Y-Ba-Cu-O (YBCO) superconductors [3]. More than two hundred papers have been published on YBCO related materials, however, the relation between elastic anomalies and superconductivity is not clarified enough.

In this study we made the experiment of ultrasonic propagation in the sintered $\mathrm{YBa}_{2} \mathrm{Cu}_{3} \mathrm{O}_{7-\mathrm{x}}$ superconductors in order to investigate the elastic anomalies caused by the various lattice-instability mechanisms. We report the ultrasonic absorption which is essentially related to the superconducting transition, and discussed the high temperature superconductivity mechanism.

\section{EXPERIMENTAL}

Two YBCO samples with different critical temperatures $\left(T_{c}\right)$ were prepared. The specifications are summarized in Table $\mathrm{I}$. The porosity of the $90-\mathrm{K} Y B C O\left(T_{c}=90 \mathrm{~K}\right)$ was as high as $25 \%$. The highly textured $60-\mathrm{K}$ YBCO $\left(\mathrm{T}_{\mathrm{c}}=60 \mathrm{~K}\right)$ was low in the porosity and oxygen content. The samples were shaped into the disks of $10 \mathrm{~mm}$ in diameter, and the two parallel surfaces were polished smoothly. The ultrasonic measurement was a standard pulse echo method. Piezoelectric quartz plates were used for generation and detection of the ultrasonic waves. The quartz plate was fastened to the YBCO sample with silicone grease. The YBCO sample was attached to a $\mathrm{Cu}$ stem and set into the cryostat. The temperature was stabilized within $0.2 \mathrm{~K}$ during the measurement. Ultrasonic attenuation coefficient was determined from the decay of ultrasonic pulse energy during the propagation. The attenuation spectrum was plotted as a function of temperature. 
Table I Specifications of the sintered $\mathrm{YBa}_{2} \mathrm{Cu}_{3} \mathrm{O}_{7-x}$ superconductors.

\begin{tabular}{llccc}
\hline $\mathrm{x}$ & & density $\left(\mathrm{g} / \mathrm{cm}^{3}\right)$ & porosity $(\%)$ & thickness $(\mathrm{cm})$ \\
\hline$\approx 0$ & $\left(\mathrm{~T}_{\mathrm{c}} \approx 90 \mathrm{~K}\right)$ & 4.7 & 25 & 0.35 \\
0.35 & $\left(\mathrm{~T}_{\mathrm{c}}=60 \mathrm{~K}\right)$ & 5.93 & 7 & 0.4 \\
\hline
\end{tabular}

\section{RESULTS}

Figure 1 shows a typical echo train in the $90-\mathrm{K}$ YBCO at longitudinal-9.7 $\mathrm{MHz}$ and $11.5 \mathrm{~K}$. The attenuation was $9.8 \mathrm{~dB} / \mathrm{cm}$, most of which was ultrasonic energy loss due to the grain-boundary scattering of the sound wave. The longitudinal and transverse velocities were $V_{1}=3.5 \mathrm{~km} / \mathrm{s}$ and $V_{t}=2.3 \mathrm{~km} / \mathrm{s}$. These were lower than those in the single crystal YBCO because of the porosity. The temperature dependence of the attenuation is plotted in Fig. 2. The background attenuation of $10 \mathrm{~dB} / \mathrm{cm}$ was almost constant in the measurement temperatures. Three attenuation peaks were observed. The attenuation change $\Delta \alpha_{1}$ in the second peak at $62 \mathrm{~K}$ was as large as $9 \mathrm{~dB} / \mathrm{cm}$, and also large attenuation in the third peak at 180 $\mathrm{K}$. The first peak at $30 \mathrm{~K}$, however, was less than $1 \mathrm{~dB} / \mathrm{cm}$. In this spectrum, no remakable attenuation change was observed at $90 \mathrm{~K}$.

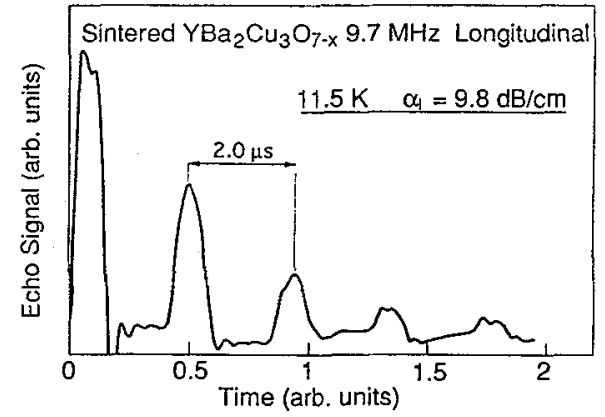

Figure 1: Ultrasonic pulse echo train in the $90-\mathrm{K}$ YBCO.

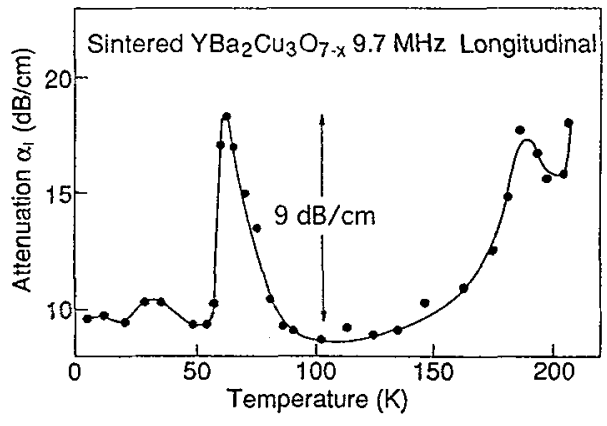

Figure 2: Temperature dependence of the ultrasonic attenuation in the $90-\mathrm{K}$ YBCO.

Figure 3 shows the echo train in the $60-\mathrm{K}$ YBCO at $14.0 \mathrm{~K}$. The longitudinal and transverse sound velocities were $V_{1}=4.9 \mathrm{~km} / \mathrm{s}$ and $V_{t}=3.2 \mathrm{~km} / \mathrm{s}$, which were very close to those in the single crystal. Small ripples appearing in the echo pattern was due to the sound wave reflection from microcracks introduced characteristically into the highly textured samples, however, they did not affect the determination of the ultrasonic parameters. The temperature dependence of the attenuation around $\mathrm{T}_{\mathrm{c}}$ is plotted in Fig. 4. The background attenuation was less than $7 \mathrm{~dB} / \mathrm{cm}$. The step-like attenuation change $\Delta \alpha_{1}$ $=2 \mathrm{~dB} / \mathrm{cm}$ was observed at $T_{c}$. A small respose was observed below $T_{c}$.

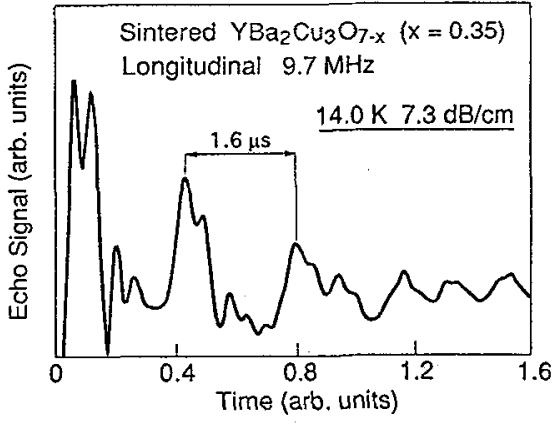

Figure 3: Ultrasonic pulse echo train in the 60-K YBCO.

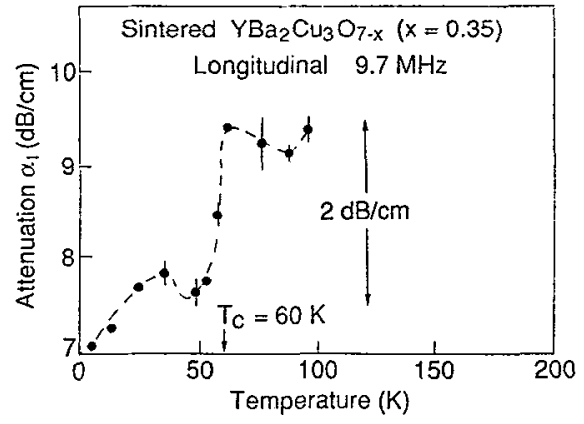

Figure 4: Temperature dependence of the ultrasonic attenuation in the $60-\mathrm{K}$ YBCO around $\mathrm{T}_{\mathrm{c}}$. 


\section{DISCUSSION}

We evaluate the porosity dependence of the Debye temperature $\Theta_{D}$ expressed by the equation,

$$
\Theta_{D}=(h / k)(9 N / 4 \pi V)^{1 / 3} /\left[1 / V_{1}^{3}+2 / V_{t}^{3}\right]^{1 / 3}
$$

$\mathrm{h}$ and $\mathrm{k}$ are the Plank's and Boltzmann's constants, respectively. The number of atoms $\mathrm{N}$ in the YBCO unit cell is 13, and the unit cell volume $V$ is $174 \times 10^{-24} \mathrm{~cm}^{3}$. From the longitudinal and transverse velocities $\left(V_{l}, V_{t}\right), \Theta_{D}$ is determined as $320 \mathrm{~K}$ for the $90-\mathrm{K}$ YBCO and $440 \mathrm{~K}$ for the $60-\mathrm{K}$ YBCO. The latter is close to the value of the single crystal. These values of $\Theta_{D}$ assure the validity of the ultrasonic experiment and the physical characteristics of the YBCO samples. Here, we must remark that $\Theta_{D}$ is determined by the velocities dependent on the porosity, and is independent of the oxygen content.

The change of the ultrasonic attenuation near $60 \mathrm{~K}$ is drastic both in the $90-\mathrm{K}$ and $60-\mathrm{K} \mathrm{YBCO}$. This peak looks as like as that observed by Cannelli and Cantelli in the internal fiction experiment on the outgassed $\mathrm{YBa}_{2} \mathrm{Cu}_{3} \mathrm{O}_{6}$ [4]. They identified it with the mechanical energy absorption by oxygen-atom jump motion between two stable sites in the $\mathrm{Cu}-\mathrm{O}$ plane. However, since our sample $\mathrm{YBa} 2 \mathrm{Cu} 3 \mathrm{O} 7-\mathrm{x}(\mathrm{x} \approx 0)$ is of highest oxygen stoichiometry, it would not be appropriate to identify our $62-\mathrm{K}$ peak simply with that of oxygen jump motion.

On the other hand, the change $\Delta \alpha_{1}=2 \mathrm{~dB} / \mathrm{cm}$ in the $60-\mathrm{K} Y B C O$ is distinctly different from the relaxation peak. The attenuation shows a rapid decay just below $T_{c}$ and a plateau above $T_{c}$, which suggests the condensation associated with the superconducting transition. We analyze this using the model of strong correlation between carriers and local lattice distortion [5]. The increase in the ultrasonic attenuation is,

$$
\Delta \alpha_{1}(\mathrm{~dB} / \mathrm{cm})=8.686 \times \mathrm{A} \omega /\left(2 \mathrm{~V}_{1}\right)
$$

in the strong correlation limit. A is the relaxation strength,

$$
A=4 n_{H} m^{*} V_{F}^{2} /\left(15 \rho V_{l}^{2}\right) .
$$

We calculate the attenuation using the parameters as follows. The carrier (hole) concentration $n_{H}$ is $1 \times 10^{21}$ $\mathrm{cm}^{-3}$ typically in the high- $\mathrm{T}_{\mathrm{c}}$ superconductors. The effective mass $\mathrm{m}^{*}$ is $7 \mathrm{~m}_{\mathrm{e}}$ determined from the de Haas van Alphen oscillation where $m_{e}$ is the free-electron mass [6], and the Fermi velocity $V_{F}$ is $7.5 \times 10^{7} \mathrm{~cm} / \mathrm{s}$ from the Landau damping in Raman experiment [7]. The mass density $\rho$ and longitudinal sound velocity $V_{1}$ are $5.93 \mathrm{~g} / \mathrm{cm}^{3}$ and $4.9 \times 10^{5} \mathrm{~cm} / \mathrm{s}$ in our $60-\mathrm{K} \mathrm{YBCO}$. The attenuation $\Delta \alpha_{1}$ (calc.) $=3.6 \mathrm{~dB} / \mathrm{cm}$ is well corresponding to the measurement $\Delta \alpha_{1}$ (meas.) $=2 \mathrm{~dB} / \mathrm{cm}$, even considering the arbitariness in the carrier concentration.

The attenuation change at $T_{c}$ was not observed in the $90-\mathrm{K}$ YBCO. This would be because the high background attenuation disturbed the detection, or, it was hidden under the skirt the large relaxation peak. We could refer an interesting report of the ultrasonic measurement [8]. Sun et al. extracted a step-like attenuation at $T_{C}$ in the 90-K YBCO of which spectral pattern was the same as in Fig. 4.

We observed the abrupt attenuation change also in the sintered $\mathrm{Bi}_{2} \mathrm{Sr}_{2} \mathrm{CaCu}_{4} \mathrm{O}_{8}(\mathrm{Bi}-2212, \mathrm{BSCCO})$ at $\mathrm{T}_{\mathrm{c}}$ (=84 K) [9]. The value of $\Delta \alpha_{1}$ was $0.9 \mathrm{~dB} / \mathrm{cm}$ at $9.7 \mathrm{MHz}$, the same extent with that of the $60-\mathrm{K} \mathrm{YBCO}$. This $\Delta \alpha_{1}$ is coincident with the internal friction measured by Huang et al. [5]. The lattice softening in the BSCCO was also observed by resonant neutron scattering and Raman scattering measurements [10,11]. Missori et al. observed the oxygen atom displacement in the BSCCO in the EXAFS experiment [12]. These experimental facts are consistent with our work, and would validate the discussion of the local lattice distortion associated with the superconductivity. 


\section{CONCLUSIONS}

The elastic properties of the sintered $\mathrm{YBa}_{2} \mathrm{Cu}_{3} \mathrm{O}_{7-\mathrm{x}}$ high- $\mathrm{T}_{\mathrm{c}}$ superconductors was investigated by ultrasonic pulse echo measurements. The porosity-dependent sound velocity and the various ultrasonic absorption were clarified. The relaxation-type large absorption was due to the jumping motion of oxygen atoms. The step-like absorption was directly related to the superconducting transition which was discussed by the model of strong correlation between carriers and local lattice distortion.

\section{References}

[1] M. Levy, Physical Acoustics XX (Academic Press, 1992)

[2] Wu-Ting and K. Fossheim, Modern Phys. B8, 275 (1993)

[3] J. Dominec, Supercond. Sci. Technol. 6, 153 (1993)

[4] G. Cannelli, R. Cantelli, F. Cordero, and F. Trequattrini, Supercond. Sci. Technol. 5, 247 (1992)

[5] Y. N. Huang, Y. N. Wang, and Z. X. Zha, Phys. Rev. B49, 1320 (1994)

[6] C. M. Fowler, B. L. Freeman, W. L. Hults, J. C. King, F. M. Mueller, and J. L Smith Phys. Rev. Lett. 68, 534 (1992)

[7] B. FriedI, C. Thomsen, H.-U. Habermeier, and M. Cardona, Solid State Commun. 81, 989 (1992)

[8] K. J. Sun and W. P. Winfree, Phys. Rev. B38, 11988 (1988)

[9] T. Takanohashi, Proceeding in PHONON 95, Sapporo, 1995 (to be published)

[10] H. A. Mook, M. Mostoller, J. A. Harvey, N. W. Hill, Phys. Rev. Lett. 65, 2712 (1990)

[11] B. Friedl, C. Thomsen, H.-U. Habermeier,, and M. Cardona, Solid State Commun. 78, 291 (1991)

[12] M. Missori et al., Physica C235-240, 1245 (1995) 